\title{
PENDIDIKAN BERBASIS REVOLUSI MENTAL BAGI MASYARAKAT DI DESA BOJONG JENGKOL
}

\author{
Nuraeni ${ }^{1}$, Hendra Gunawan, Ivan Fadillah ${ }^{2}$ \\ nuraeni@uika-bogor.ac.id
}

Dosen Fakultas Keguruan dan Ilmu Pendidikan ${ }^{1}$, Mahasiswa KKN Kelompok 09 Tahun $2018^{2}$

\begin{abstract}
ABSTRAK
Pendidikan dan kesehatan menjadi salah satu faktor yang sangat dibutuhkan dalam meningkatkan kualitas sumber daya manusia, baik di lingkungan masyarakat umum maupun khususnya di desa Bojong Jengkol Kecamatan Ciampea Kabupaten Bogor. Namun dengan berbagai kendala yang dihadapi seperti salah satunya permasalahan internal di beberapa RW, maka perlu ditingkatkan kesadaran akan pentingnya memperoleh tingkat pendidikan dan kesehatan yang berkualitas. Dengan cara revolusi mental melalui pendekatan agama dan sosial sehingga diharapkan dapat merubah pola pikir masyarakat.
\end{abstract}

\section{Kata kunci: Pendidikan, Kesehatan dan Revolusi Mental}

\section{PENDAHULUAN}

Revolusi mental pertama kali digunakan oleh Presiden Soekarno pada tahun 1957 ketika revolusi nasional sedang berhenti. Gerakan itu ditujukan untuk menggembleng manusia Indonesia agar menjadi manusia baru yang berhati putih, berkemauan baja, bersemangat elang rajawali, berjiwa api yang menyala-nyala. Di dalamnya terkandung nilai esensi yang meliputi etos kemajuan, etika kerja, motivasi berprestasi, disiplin, taat hukum dan aturan, berpandangan optimistis, produktif dan inovatif, adaptif, kerja sama dan gotong royong, dan berorientasi pada kebajikan publik dan kemaslahatan umum.

Nilai esensi diatas, sejalan dengan nilai karakter yang merupakan orientasi dasar dalam sebuah penyelenggaraan pendidikan. Ia merupakan 'roh' yang menghidupkan semua komponen didalamnya. Tanpanya, proses pembelajaran lebih menyerupai tukar-menukar informasi semata. Didalam 'karakter' ada unsur 'nilai' sebagai alat takar pendidikan. Nilai yang dimaksud adalah 'nilai kemanusiaan'. Nilai itulah yang digunakan untuk membangun karakter yang bersifat manusiawi.

Namun demikian, realitas penyelenggaraan pendidikan di berbagai lembaga pendidikan tidak lagi dibangun atas dasar nilai kemanusiaan tersebut. Tetapi, justru dibangun atas dasar nilai material yang bersifat hedonis dan pragmatis. Bukti yang dapat ditujukan antara lain: tawuran pelajar dan tawuran mahasiswa dan bahkan saling membunuh diantara mereka, maraknya korupsi di 
berbagai sekat, baik itu di dalam pendidikan seperti kegiatan mencontek yang mana hal tersebut merupakan bibit dalam terbentuknya korupsi, mereka lebih mengutamakan 'nilai' dibandingkan 'karakter'. Dan korupsi terus terjadi di wilayah hukum dan pemerintahan yang mana hal tersebut menjadi suatu hal yang lumrah bagi para pejabat dan para pemangku kekuasaan.

Dalam konteks tersebut, para stakeholder pendidikan berupaya keras mencari solusi untuk mengembalikan 'nilai kemanusiaan' tersebut di dalam pendidikan dan pengajaran serta dalam bidang kesehatan agar pemikiran manusia lebih jernih dalam berpikir dan mengambil keputusan. Upaya yang dilakukan misalnya dengan menggali nilai kearifan lokal yang kemudian diintegrasikan didalam proses pembelajaran. Diharapkan kemudian terbentuknya karakter peserta didik yang manusiawi tersebut.

Dalam tahapan terbangunnya revolusi mental ini, tahapan pertama adalah kepada subyek didik perlu ditumbuhkan kesadaran otonominya untuk memilih dan membuat keputusan. Otonomi membuat keputusan menjadi omong kosong bila tidak dilengkapi dengan ability (kemampuan) atau kecakapan yang diperlukan untuk membuat keputusan. Dalam era yang semakin kompleks diperlukan saling membantu dan mengisi antarwarga masyarakat, sehingga pada tahap pertama ini diperlukan watak demokratis. Tampilan tahap pertama adalah sosok subyek-didik yang memiliki ability sekaligus menyadari otonominya, dan sekaligus menyadari peran kontributif satu sama lain dalam menampilkan otonomi masing-masing. (Muhadjir, 2000).

Dalam era dengan percepatan perubahan yang luar biasa, pada tahap kedua proses pendidikan nilai diperlukan subyek-didik yang selalu dapat berkreasi dalam aksinya, dan kreatif dalam karyanya. Kreativitas tersebut lebih jauh diperlukan agar memiliki kemampuan untuk berkompetisi. Kompetisi yang bijak, bukan saling mematikan, tetapi menghargai secara sportif kelebihan orang lain. Menjadi lebih bijak lagi, bila watak kompetitif bukan untuk saling mengalahkan, tetapi saling memberikan kontribusi lebih baik : berlomba dalam kebajikan. Bijak atau wise memerlukan kriteria yang jelas secara substantif. (Muhadjir, 2000)

Dalam era dunia yang semakin mengglobal, pada tahap ketiga proses pendidikan diperlukan tampilan yang memiliki harkat (dignity), martabat (pride), dan keunggulan (excellence). Dengan demikian dapat terbentuknya kemandirian (independency). Proses pendidikan perlu ditumbuhkan watak kemandirian dan diakhiri dengan tampilan unggul. Unggul mencakup makna unggul komplementatif, unggul komparatif, dan unggul kompetitif. (Muhadjir, 2000).

Pada tahap keempat, proses pendidikan subyek-didik perlu tampil dalam performansi integratif-human, sehingga harkat, martabat, dan keunggulan itu dalam kriteria: human universal dan human teistik. (Muhadjir, 2000).

Dengan adanya pembangunan yang 
dilakukan di Indonesia, dengan mencakup beberapa bidang diantaranya adalah bidang sosial, kesehatan, pendidikan, ekonomi, hukum, Agama dan teknologi tepat guna. Tahapan revolusi mental diatas dapat diterapkan untuk mencapai manusia yang berdaulat. Namun hal ini belum mampu dioptimalkan oleh pemerintah baik di kecamatan maupun desa, dikarenakan kurangnya tingkat pendidikan SDM yang belum memadai dan faktor lainnya yang mempengaruhi.

Seperti halnya di Desa Bojong Jengkol Kecamatan Ciampea Kabupaten Bogor, yang memiliki kendala pada kualitas sumber daya manusia, baik ditingkat pendidikan maupun kesehatan. Maka dari itu, kami dalam pelaksanaan kegiatan Kuliah Kerja Nyata Kelompok 09 Universitas Ibn Khaldun Bogor berusaha melakukan perubahan pola pikir pada masyarakat sekitar, sehingga dapat terwujudnya perubahan yang lebih baik pada tingkat pendidikan dan kesehatan sebagai pijakan awal terbentuknya pemikiran yang lebih jernih dan maju.

\section{Keadaan Geografis}

Secara geografis Desa Bojong Jengkol merupakan salah satu wilayah Ciampea kabupaten Bogor dengan luas wilayah kurang lebih 212 Ha. Terbagi atas 12 rukun warga dan 34 rukun tetangga. Batas wilayah Desa Bojong Jengkol adalah sebagai berikut:

\begin{tabular}{|c|c|c|}
\hline No & Arah & Berbatasan \\
\hline 1 & Utara & Desa Benteng \\
\hline 2 & Timur & $\begin{array}{c}\text { Desa Cibanteng dan } \\
\text { Desa Cihideung Udik }\end{array}$ \\
\hline 3 & Selatan & $\begin{array}{c}\text { Desa Cinangka dan } \\
\text { Desa Cinangneng } \\
\text { Kecamatan Tenjolaya }\end{array}$ \\
\hline 4 & Barat & Desa Tegal Waru \\
\hline
\end{tabular}

\section{Kondisi Masyarakat}

\begin{tabular}{|c|l|c|}
\hline No & Jumlah Penduduk & Jumlah \\
\hline 1 & Jumlah Laki-laki & 5.074 Jiwa \\
\hline 2 & Jumlah Perempuan & 4.630 Jiwa \\
\hline 3 & Jumlah Total & 9.704 Jiwa \\
\hline \multicolumn{2}{|l|}{ Jumlah Kepala Keluarga } & 2.567 KK \\
\hline
\end{tabular}

Tingkat Pendidikan

\begin{tabular}{|l|l|c|}
\hline No & Tingkatan & Jumlah \\
\hline 1 & Tidak tamat SD & 45 \\
\hline 2 & Tamat SD & 2.319 \\
\hline 3 & Tamat SMP & 1.995 \\
\hline 4 & Tamat SMA & 2.032 \\
\hline 5 & Akademik & 54 \\
\hline 6 & Sarjana & 63 \\
\hline 7 & Magister & 20 \\
\hline 8 & Lain-lain & 3.176 \\
\hline \multicolumn{2}{|l|}{ Jumlah Total } & $\mathbf{9 . 7 0 4}$ \\
\hline
\end{tabular}


Volume 02 Nomor 04, Desember 2018

\section{Mata Pencaharian}

\begin{tabular}{|c|c|c|}
\hline No & Pekerjaan & Jumlah \\
\hline 1 & Petani & 284 \\
\hline 2 & Buruh tani & 783 \\
\hline 3 & Pegawai Negeri Sipil & 259 \\
\hline 4 & $\begin{array}{l}\text { Pengrajin industri rumah } \\
\text { tangga }\end{array}$ & 131 \\
\hline 5 & Pedagang keliling & 1.360 \\
\hline 6 & Peternak & 23 \\
\hline 7 & Montir & 273 \\
\hline 8 & Pembantu Rumah Tangga & 125 \\
\hline 9 & TNI & 19 \\
\hline 10 & POLRI & 8 \\
\hline 11 & $\begin{array}{l}\text { Pensiunan } \\
\text { PNS/TNI/POLRI }\end{array}$ & 6 \\
\hline 12 & $\begin{array}{l}\text { Pengusaha kecil dan } \\
\text { menengah }\end{array}$ & 310 \\
\hline 13 & Pengusaha besar & 2 \\
\hline
\end{tabular}




\section{Metode Pendekatan}

Pendekatan yang digunakan dalam kegiatan ini adalah :

a. Pendekatan religius, yaitu pendekatan dimana seluruh warga Desa Bojong Jengkol khususnya kampung Bojong Jengkol RW 04 menghadiri kegiatan pengajian rutin yang juga dihadiri oleh para mahasiswa pelaksana $\mathrm{KKN}$;

b. Pendekatan organisasi, yaitu pendekatan dimana setiap pelaksana kegiatan selalu dikoordinasikan dengan aparat setempat tentang peningkatan kualitas sumber daya manusia melalui pedidikan dan kesehatan;

c. Pendekatan kekerabatan, yaitu pembinaan yang dilakukan senantiasa dikaitkan dengan kesadaran akan pentingnya pendidikan dan kesehatan sehingga kualitas masyarakatnya menjadi semakin baik;

d. Pendekatan berdasarkan karakter masyarakat, yaitu pembinaan yang dilakukan sesuai dengan kondisi masyarakat setempat sehingga mereka dapat berpartisipasi langsung terhadap kegiatan yang akan dilaksanakan selama KKN.

\section{Partisipasi Masyarakat}

Partisipasi masyarakat yang dapat dilakukan dalam kegiatan ini adalah sebagai berikut :

a. Mempersiapkan warga yang bersedia mengikuti pembinaan baik tentang pendidikan kesehatan maupun motivasi lainnya; b. Mempersiapkan tempat untuk melakukan pembinaan dengan berkoordinasi kepada tokoh masyarakat setempat sehingga kegiatan dapat terlaksana dengan baik;

c. Mempersiapkan tempat untuk melakukan penyuluhan maupun seminar yang bertujuan untuk meningkatkan kualitas sumber daya manusia masyarakat sekitar;

d. Pelaksanaan kegiatan pembinaan, penyuluhan maupun seminar tentang pendidikan, kesehatan, sosial dan ekonomi maupun teknologi tepat guna serta dilakukannya monitoring pelaksanaan.

\section{Langkah Evaluasi}

Evaluasi yang dilakukan terdiri dari:

a. Evaluasi proses, evaluasi ini dilakukan setiap pekan baik oleh anggota kelompok maupun dengan masyarakat secara bersama-sama. Evaluasi ini juga berkaitan dengan perencanaan, pelaksanaan dan monitoring kegiatan;

b. Evaluasi hasil, evaluasi ini ditujukan untuk meningkatkan kesadaran tentang pentingnya pendidikan, kesehatan maupun sosial dan ekonomi kepada warga. Evaluasi hasil dilakukan setelah selesai setiap kegiatan yang dilaksanakan;

c. Evaluasi dampak, evaluasi ini bertujuan untuk melihat efektivitas pelaksanaan kegiatan terhadap keberlangsungan kehidupan masyarakat sekitar yang dilakukan diakhir pelaksanaan KKN. 


\section{REALISASI PROGRAM}

Dalam pelaksanaan kegiatan $\mathrm{KKN}$ Tematik Terintegrasi Universitas Ibn Khaldun Bogor di Desa Bojong Jengkol kecamatan Ciampea Kabupaten Bogor, kami melaksanakan beberapa kegiatan yang merupakan program kerja kami di desa tersebut. Alhamdulillah kegiatan-kegiatan tersebut dapat terlaksana dengan baik dan lancar sesuai rencana diantaranya:
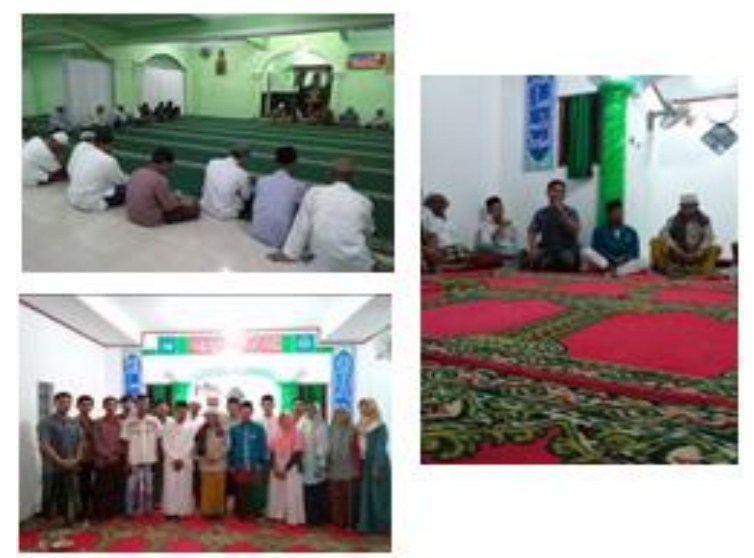

a. Kegiatan pengajian rutin bapak-bapak dan pemuda pemudi yang diadakan di Masjid maupun Mushola yang terdapat di lingkungan RW 04 desa Bojong Jengkol;

b. Pengajian ibu-ibu yang dilaksanakan setiap seminggu dua kali di majlis ta'lim maupun Pondok Pesantren;

c. Kegiatan bimbingan belajar yang dilaksanakan di posko kelompok 9 KKN UIKA bogor setiap harinya;
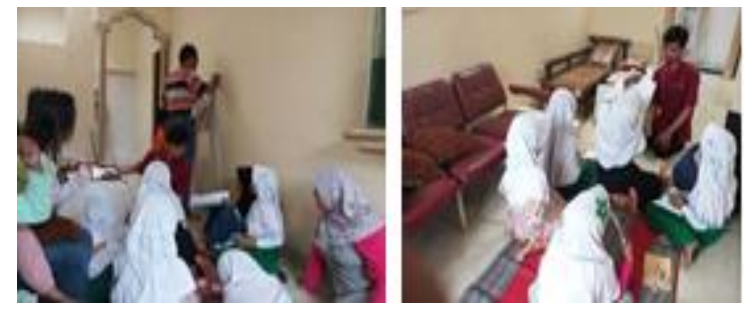

d. Kegiatan les privat, baik menggambar, bahasa inggris maupun matematika yang dilakukan setiap harinya di sore hari sehingga bermanfaat untuk meningkatkan pengetahuan anak-anak di lingkungan masyarakat desa Bojong Jengkol;

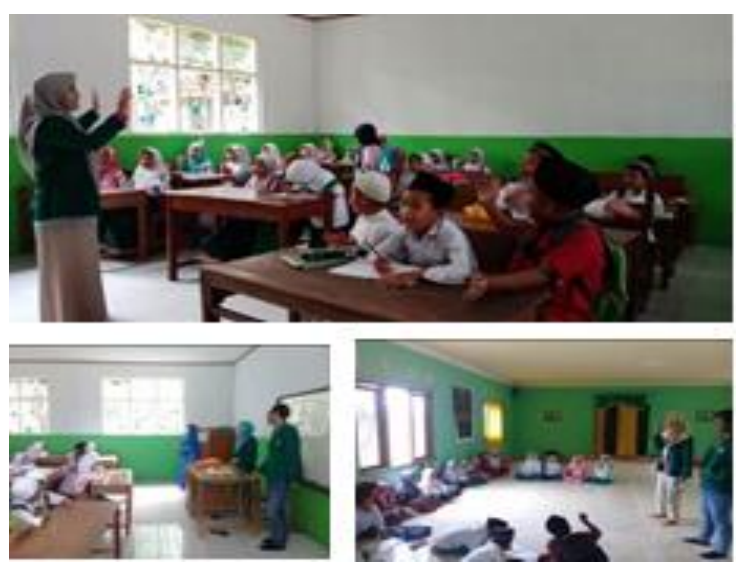

e. Kegiatan belajar mengajar di beberapa sekolah (PAUD, TK, Madrasah Diniah dan Sekolah Dasar), pembelajaran dengan cara memotivasi siswa/siswi agar lebih mementingkan pendidikan demi tercapainya cita-cita. Selain itu metode pembelajaran yang lebih baru disampaikan dengan harapan materi dapat terserap dengan cepat dan baik oleh siswa/siswi;
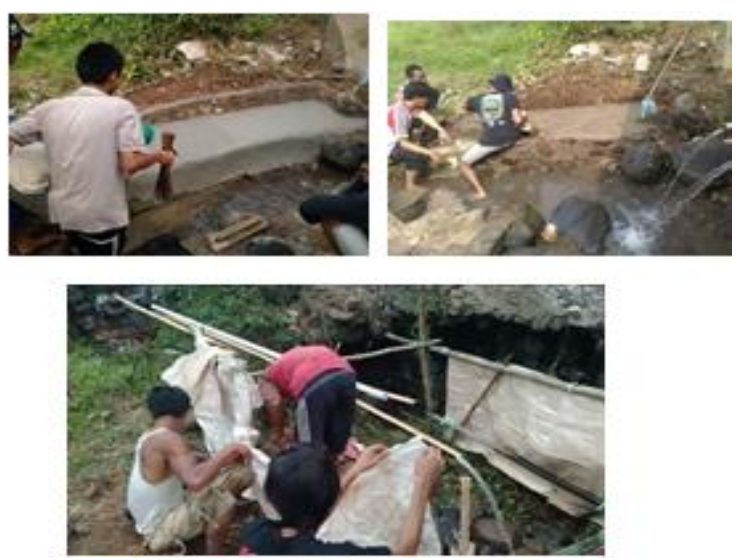

f. Kegiatan kerja bakti bersama-sama dengan warga dalam pembuatan pancoran air bersih untuk meningkatkan kualitas kesehatan 
masyarakat;

g. Adanya jalan sehat dalam rangka menyambut peringatan HUT RI yang ke-73;
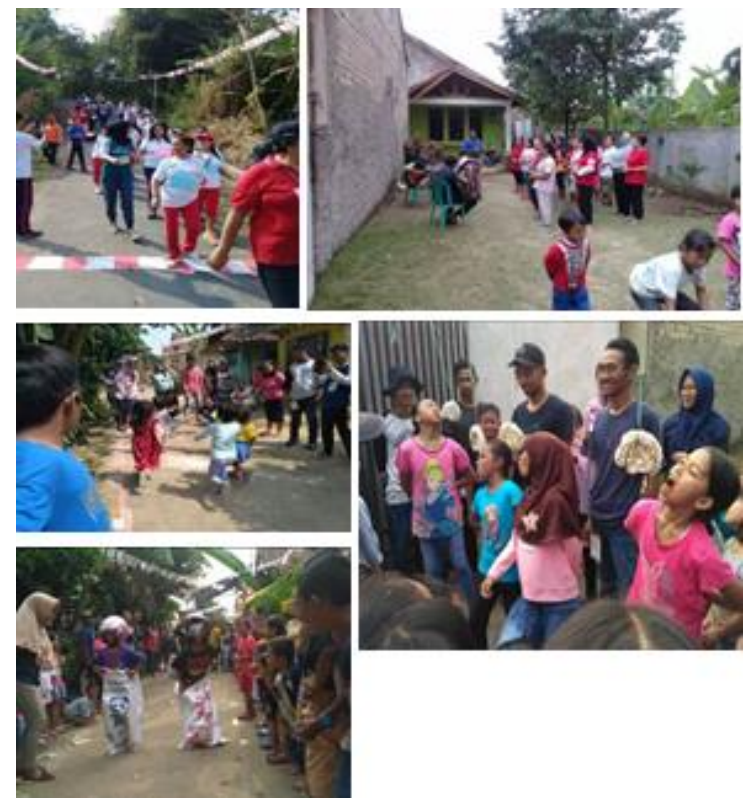

h. Perayaan 17 Agustus 2018 di Desa Bojong Jengkol ikut berpartisipasi sebagai panitia pelaksana HUT RI ke-73;

i. Pembuatan Zebra Cross dijalan depan Masjid utama kampung Bojong Jengkol khususnya RT 01;

j. Pemasangan Bel di Madrasah Diniah untuk meningkatkan kualitas kedisiplinan baik untuk siswa/siswi ataupun gurunya;
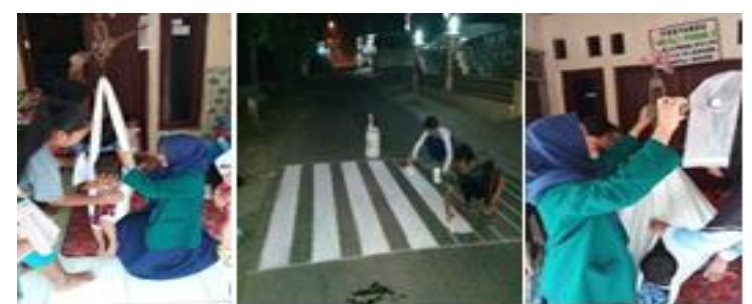

k. Membantu kader dalam kegiatan posyandu;
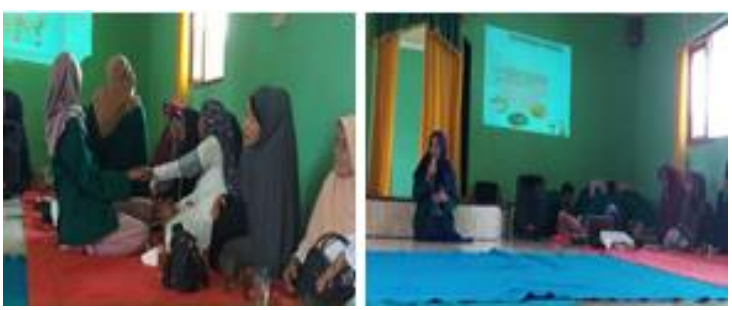

1. Melaksanakan kegiatan penyuluhan penyakit hipertensi dan cek kesehatan Lansia bagi masyarakat;

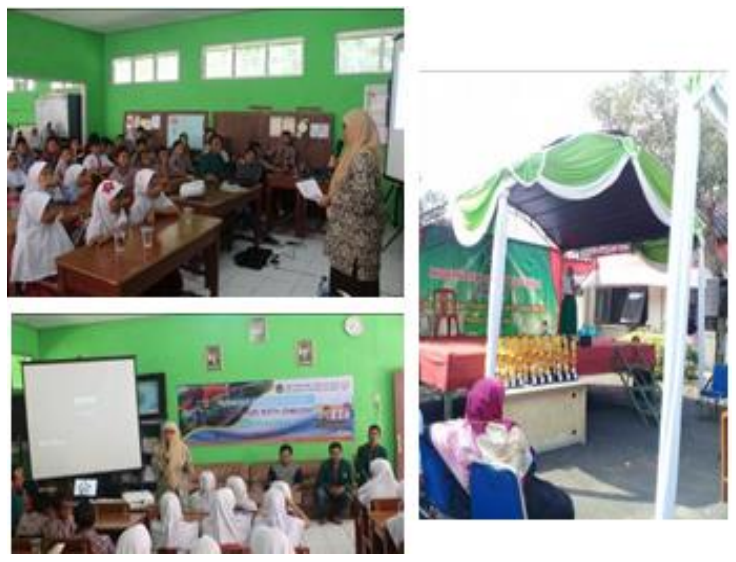

m. Penyuluhan PHBS yaitu kegiatan cuci tangan di Madrasah Diniah Mathlaul Anwar dan sikat gigi yang baik dan benar di TK Arofah;

n. Penyuluhan sampah Organik dan Non-organik di Madrasah Diniah Mathlaul Anwar serta penyerahan tempat sampah untuk sekolah;

o. Pemasangan mading di sekolah;

p. Seminar Bahasa Inggris dengan tema 'Having Fun With English' sekaligus training motivasi terhadap siswa siswi tentang pentingnya berbahasa Inggris;

q. Mendampingi siswa/siswi mengikuti lomba Porsadin sekecamatan Ciampea Kabupaten Bogor; 


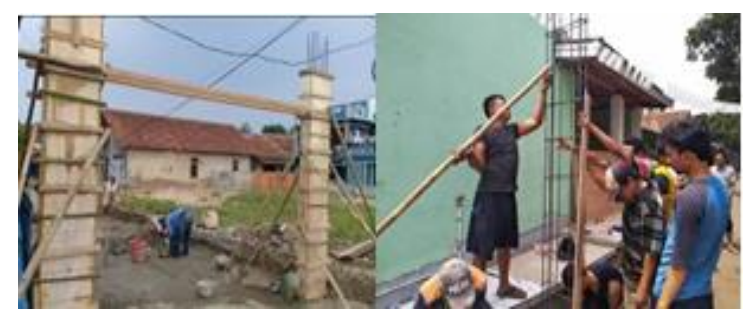

r. Pembuatan gapura kampung Bojong Jengkol Rw 04 desa Bojong Jengkol kecamatan Ciampea kabupaten Bogor;

s. Perpisahan dengan masyarakat sekitar di desa Bojong Jengkol sekaligus pemberian kenang-kenangan berupa wakaf Al-Qur'an;

\section{KESIMPULAN}

Program kelompok 9 KKN Tematik Terintegrasi tahun 2018 terlaksana dengan baik dan memberikan dampak yang cukup positif bagi masyarakat desa Bojong Jengkol. Program yang dilaksanakan sesuai dengan bidang program kerja yang diperlukan seperti bidang pendidikan, bidang ekonomi, bidang agama dan bidang kesehatan serta bidang teknik:

Bidang Pendidikan

a. Meningkatkan kesadaran akan pentingnya tingkat pendidikan bagi masyarakat khususnya siswa/siswi agar mereka dapat terus belajar sepanjang hayat;

b. Meningkatkan semangat belajar para siswa/siswi dengan cara penyampaian materi yang lebih kreatif;

c. Menambah ilmu pengetahuan siswa/siswi serta membuat mereka termotivasi untuk melanjutkan pendidikan yang lebih tinggi.

Bidang Ekonomi

a. Meningkatkan ekonomi kreatif masyarakat desa Bojong Jengkol;

b. Meningkatkan kesadaran masyarakat akan pentingnya dana swadaya masyarakat demi pembangunan di desa tersebut;

Bidang Kesehatan

a. Merubah kebiasaan masyarakat membuang sampah sembarangan;

b. Meningkatkan kesadaran akan pentingnya menjaga kebersihan diri seperti mencuci tangan dan sikat gigi ;

Bidang Agama

a. Mengajak pemuda/pemudi untuk meramaikan kegiatan pengajian didesa Bojong Jengkol;

b. Memberikan motivasi kepada pemuda/pemudi sehingga mereka dapat memaknai pengajian yang dilakukan bukan hanya sebagai pendengar;

c. Ikut serta berpartisipasi dalam setiap kegiatan agama yang dilakukan di lingkungan masjid maupun mushola.

Bidang Teknik

a. Pembuatan Zebra Cross dalam rangka melindungi pengguna jalan di lingkungan RW 04 Desa Bojong Jengkol;

b. Mempermudah masyarakat mendapatkan air untuk memenuhi kebutuhan melalui pancoran air yang dibuat secara gotong royong;

c. Meningkatkan kedisiplinan siswa/siswi maupun para guru dalam pelaksanaan kegiatan belajar mengajar dengan adanya Bel;

d. Meningkatkan kreatifitas siswa/siswi dengan adanya media pembelajaran yang memadai seperti salah satunya 
adanya mading atau papan informasi sekolah.

\section{SARAN}

Berdasarkan hasil kegiatan $\mathrm{KKN}$ Tematik Terintegrasi UIKA Bogor 2018 diharapkan masyarakat Desa Bojong Jengkol Kecamatan Ciampea Kabupaten Bogor dapat termotivasi untuk meningkatkan kualitas sumber daya manusianya baik dilihat dari tingkat pendidikannya maupun kesehatannya. Selain itu diharapkan juga setiap bidang dalam pembangunan seperti bidang pendidikan, kesehatan, agama, ekonomi dan teknik dapat ditingkatkan kualitasnya serta memicu masyarakat untuk ikut berperan aktif dalam meningkatkan bidang-bidang tersebut.

\section{REFERENSI}

Administrasi profil Desa Bojong Jengkol Kecamatan Ciampea Kabupaten Bogor

Petunjuk pelaksanaan KKN Tematik Terintegrasi 2018, LPPM UIKA Bogor 2018, UIKA Press

https://id.wikipedia.org/wiki/Kuliah_kerja nyata

https://www.artikelsiana.com/2015/08/pen gertian-pendidikan-tujuan-manfaat.ht $\underline{\mathrm{ml}}$

https://www.researchgate.net/publication/3 $\underline{22397773}$ 